turbance. This swelling of the epiphyses, with or without pain, as the lesion giving rise to it was a congenital one, might appear in infants of any age. When the enlargement of the epiphyses was of any considerable size, however, it usually occurred in infants of from three to six months old. but was rare after the latter age. Suppuration of epiphysial disease of the long bones was rare in infants under a year old. "In older children," he continued, "suppuration over" the ends of the long bones is, perhaps, commoner than in young infants, owing possibly to walking and other uses of the limbs proving prejudicial to a previous epiphysitis not entirely cleared up. A symmetrical suppurative epiphysitis in children between $I$ and 3 years old is to me sufficient to warrant a strong suspicion of syphilis for its causation. In contradistinction to the case of the long bones, suppuration arising from epiphysitis of the phalanges, 'syphilitic dactylitis,' is not very rare."

\section{ACQUIRED SYPHILIS.}

After quoting the differences between inherited and acquired syphilis in the child, as enumerated by Kassowitz, Dr. Coutts said: "As far as my experience goes the commonest eruption in acquired syphilis in infants, as in adults, is the well-known roseola and its usual distribution, the same at all ages, namely, the front of the chest, the abdomen, and to a less degree the flexor aspects of the limbs. This syphilitic roseola, admittedly rare in inherited cases, was the form of eruption in seven out of my eight cases. In the remaining one, an infant that had acquired a chancre on the back of the neck from kissing by a syphilitic aunt, and that had in its turn given its mother a chancre on her breast, a universal small pustular eruption broke out all over the body. Along with the rash, too, in most of my cases $I$ found a condition of throat identical with that occurring in adult syphilis: this is in marked contrast with what happens in the inherited form, where the throat remains, as a rule, unaffected. The chief peculiarities of the symptoms, however, in acquired syphilis in infancy are the scantiness and evanescent nature of the eruption, which may be easily missed, and the subsequent early and luxuriant growth of condylomata." He insisted upon the importance of recognising that in acquired syphilis in infants a chancre must occur. In connection with charges of the conveyance of syphilis by vaccination this was a most necessary point to bear in mind.

Infection in Inherited Syphilis: Colles's Law.

After referring to the opinion strongly expressed by Colles, and by Diday and other French observers, to the effect that inherited syphilis was eminently infectious, Dr. Coutts quoted the experience of the Shadwell Hospital for Children, covering many thousands of cases drawn from a class in which syphilitic babies were often indiscriminately suckled by other women than the mother and kissed and fondled by many other persons. Only five examples of the incurrence of syphilis could be discovered, and of these four would fall into the category of exceptions to Colles's law that a mother was not infected by her own syphilitic infant. "That inherited syphilis," he continued, "is occasionally contagious is certain, but it is equally certain, I would contend, that the virulence of such contagion has been grossly and vastly overestimated. It is impossible to reconcile the experience of certain French writers in this respect with our experience in this country, even when the greater frequency of wet nursing in France is fully admitted. There are certain reasons, or suggestions rather, by which I think the infre. quency of the contraction of syphilis from infants suffering from the inherited complaint can be partially explained. The syphilis in such infants, it must be remembered, dates from conception and not from birth, and at the age at which symptoms appear such a syphilis is generally of about a year's s $t$ inding, and may have lost some of its pristine virulence during both uterine and extrauterine existence. In marked contrast to the rarity of infection from inherited syphilis is its frequency from the acquired form in infants. Only one instance is within my perconal knowledge where a syphilis acquired by an infant, was not communicated to one or more persons brought into - ontact with the child. Numerons instances ar: on reco d, from the time of Ambroise 7
Paré onwards, where infantile acquired syphilis has been the cause of severe outbreaks amongst relatives and friends. Recently I learnt of one in the Last of London where acquired syphilis in a child spread to tive others in the same family besides strangers. Colles's law," he continued, "in reality consists of two separate parts, the one that the mother of an infant with inherited syphilis cannot contract the disease from her own child, and the other that such an infant would almost infallibly contaminate a healthy wet nurse. The fact of the inclusion of this second proposition is generally forgotten by writers contending for the absolute validity of the law. In dealing with the contagiousness of inherited syphilis, I endeavoured to show that this part of the so-called law is far from true. It may well be, then, that the main safety of the mother lies in the little liability of the infant to transmit the disease rather than in some protective quality residing in herself, due to the fact of her having borne a syphilitic infant. For my part, I think both such factors possibly conduce to the safety of the mother. Is the first part of Colles's law absolute? Has an infant with inherited syphilis never contaminated the mother? In Colles's own practice, and in those of others since his day, cases have from time to time occurred which were apparently exceptions to the law. Some of these cases are so imperfectly recorded that discussion of them is hardly called for. Others, on the contrary, Dr. George Ogilvie writes, ' are as conclusive as any recorded clinical facts can be.' Fournier, somewhat grudgingly it would seem to me, admits the validity of some such cases, and he would appear to regard the subject of exceptions to Colles's law as of little practical importance on account of their extremely exceptional character. Mr. Hutchinson has lately stated that he not only admits the possibility but the probability of these exceptions. I am the more pleased at this admission in that it places him in accord with Fournier and other authorities in the matter, and that it is also in some sense a further justification for the belief in myself and others that we have actually met with exceptions to Colles's law. Mr. Hutchinson's sole contention is, I believe, that as yet no exceptions have been recorded worthy of trust. I am unwilling to differ from him, but I must state my conviction that Dr. George Ogilvie's admirable paper at the Royal Medical and Chirurgica! Society is conclusive on the point. Gianted the possibility of exceptions to Colles's law, ought such eminently infrequent occurrences to largely modify our practice in allowing apparently healthy mothers to suckle tainted infants? Personally, I should say decidedly not. If ever legislation for the many to the detriment of a limited few is justifiable, the case in question calls for it. Following in the same path as Henoch, the only limitations I would place on suckling by mother or wet nurse would be the presence of excoriations on her nipples and that of ulcerations or fissures about the mouth of the infected infant.

\section{CIRRHOSIS OF THE LIVER AND ICTERUS OF FOUR YEARS' DURATION.}

WITH REMARKS ON BILIARY CIRRHOSIS.

By F. PARKES WEBER, M.D.,

Physician to the German Hospital.

THE case may be shortly given as follows:

MIrs. M. L., aged 55, suffered from jaundice for about the last four years of her life. There seems to be no doubt that the jaundice had really lasted all this time, though the listory regarding the symptoms at the commencement is defective. Apparently there lad been no definite biliary colic, but pain in the left side. She had never had jaundice prebiliary colic, but pain in the left side. She had never had jaundice pre-
viously. Slie had had no children and no miscarriages. There was no viously. She hiad had no children (?). A friend connected the onset with mental troubles following her hiusband's death. I first saw her in November, 1894, at which time she had already been jaundiced for about three years; $;$ she was admitted from the out-patients at the German Hospital by Dr. J. P. Zum Busch, then senior resident medical officer who having watched the case for two years, considered it to be one of hypertrophic cirrlosis, due to some obstruction in the bile ducts. At that time the jaundice was deep, and she had xanthelasma palpebrarum, and a diffuse xanthoma of the skin over large areas at both sides of the neck; the affected skin in the neck was not raised above the general level.whereas the affected portion of the eyelids was, as usual. somewhat level. Whereas the affected portion of the eyelids was, as usual, somewhat
raised above the skin arouud. The liver appeared to be hard, and uniraised above the skin arouud. The liver appeared to be hard, and uni-
formly much enlarged, the dulness extending from the fittl rib to the
umbilical level. The spleen was not felt distinctlv. There was no ascites, bi $t$ s me c derra about t!le anllies was noticed. The patient had no rain 
excepting a little in her joints, but she was tormented by a pruritus very little affected by treatment. Over the base of the right lung there was slightly impaired resonance, with crepitation, due to pressure from the liver (?). On one occasion there was slight epistaxis.

She jeft the German Hospital on January roth, is 895 , in much the same She left the German Hospital on January roth, I895, in much the same
condition as she entered it, but was readmitted ou November rgth, 1895 . in a condition of general weakness and prostration. The itcling had practically left her, but the skin seemed darker, as if more pigment had been deposited in it than when she was previously under observation. Some ascites was now observed, and there was more oedema of the lower extremities. The liver could no longer be distinctly palpated. The stools were colourless, often loose and accompanied by a little blood, probably of hæmorrhoidal origin. The urine was deeply bile-coloured and besides giving the ordinary Gmelin's reaction with nitric acid, turned green immediately on the addition of acetic acid, 1 even in the cold, but when heated a much smaller quantity of acetic acid was required to produce the reaction. There was no sugar or albumen in the urine until
the last days of life, when some albumen, blood cells and casts, were found present.

At no time was there any dilatation of the veins (caput medusæ) over the front of the abdomen. The ascites increased somewhat, but was never sufficient to render tapping of the abdomen advisable, whereas the nedema of the lower extremities became very great. The temperature never reached $100^{\circ} \mathrm{F}$. During the last days patient $\mathrm{gra}$

Necropsy. - The calvarium showed large, ovoid, sharply-defined symmetrical areas of extreme thinning in the parietal bones. a condition occurring occasionally in elderly persons, and apparently without special pathological significance. In the Hunterian Museum are Egyptian and pathological significance. In the Hunterian Museum are Egyptian and No valvular disease : no hypertrophy; muscular substance normal ; a verv moderate amount of atheroma and fatty degeneration in the aorta, pulmonary arteries, and one of the coronaries. Lungs: old pleuritic adhemonary arteries, and one of the coronaries. Lungs: Old pleuritic adhesions: hypostatic congestion. Abdomen: A moderate amount of slightly turbid, ascitic fluid in the peritoneum. Liver: Weighed 54 onnces : its
substance was tougl, its surface puckered or granular. and its colour substance was tough, its surface puckered or granular. and its colour
greenish. Veins and arteries natural. The gall bladder was rather dilated and hypertrophied, and contained a thin, very faintly greenish fluid ; the cystic and hepatic ducts were pervious. The common bile fluid ; the cystic and hepatic ducts were pervious. The common bile in the "ampulla, or diverticulum of Vater," were two black gall stones, in the "ampula, or diverticulum of Vater," were two black gall stones, the larger one having the size of a small cherry stone; there was no ulceration in the neighbourhood of the stones. The interior of the duodenum was normal. Some of the contents of the gall bladder could be squeezed out of the orifice of the common bile duct, before any part of the bile duct had been opened. Under the microscope sections of the liver (sections were cut from three different pieces of the liver) presented the appearances of ordinary cirrhosis; the distribution of fibrous tissu in the number of the small bile ducts. I must thank $\mathrm{Mr}$. Targett and in the number of the sinall bile ducts. I must thank Mr. Targett and Dr. Rolleston for their kindness respectively in looking at the liver and sections. Spleen, uniformly enlarged. weighed 20 ounces; substance red. rather pulpy; excess of trabecula could be seen by the naked eye. Kidneys : Apparently some swelling of the glandular substance; capsule made. Pancreas macroscopically appeared normal. Stomach: The
macous membrane appeared nearly normal, and was not discoloured.

The cause of the hepatic cirrhosis is the doubtful feature and point of interest in the present case. The liver resembled a liver of ordinary cirrhosis, but was rather large. weighed 54 ounces, and was of a greenish colour. I do not think that the woman was a really alcoholic subject, although the history was doubtful on the point; her manner and general appearance,whilst in the hospital certainly were not suggestive of chronic alcoholism. The absence of enlargement of the veins (caput medusæ) over the front of the abdomen, and the small degree of ascites, even at the time of death, both speak, I believe, against the supposition that the disease was due to alcohol; moreover, the mucous membrane of the stomach appeared normal, as it is not likely to apnear in cases of chronic alcoholism. My colleague, Dr. Michels, pointed out that the scantiness of ascitic effusion was remarkable, when compared with the enlargement of the spleen (weight, 20 ounces), though the latter was doubtless in part caused by obstruction in the portal circulation. This may be explained by supposing that the great amount of ascites in ordinary cases of alcoholic hepatic cirrhosis is due not merely to obstruction in the portal circulation, but also in part to an abnormal state of the peritoneal serous membrane, a sort of chronic peritonitis, brought about by alcoholic habits, and predisposing it to the pouring out of ascitic fluid. This predisposing factor of ascites would be absent if, as I believe, the hepatic cirrhosis in the present case was not due to alcohol.

The question may be asked, Could the small gall stones found in the common bile duct, have been there for four years,

I I do not know in what proportion of jaundice cases this reaction with acetic acid takes place so easily. I have only noticed it once to such a degree, and that was in a case of rapidly fatal acute yellow atrophy of the liver. With the permission of Sir Dyce Duckworth I published notes of the case in the Lancet ( 1892 , vol. i, p. 630), but did not at the time consider occasionally to turn green without the addition of any reagents. and by hindering the flow of bile have given rise to a "biliary cirrhosis"? Against such a view it may be objected that there was no ulceration in the duct, such as one might expect to be caused by the continued presence of gall stones for so long a period; moreover, at the post-mortem examination the contents of the gall bladder could be squeezed out into the duodenum.

Neither of these objections is sufficient. The obstruction to the bile flow may not have been complete at all times, but may have been intermittent, and may yet have given rise to cirrhosis, or during life it may have been complete though after death some bile could be squeezed past it. ${ }^{2}$ Ulceration does not necessarily take place around a gall stone, but depends doubtless to a great extent on the general health of the patient, and on invasion by pyogenic microbes. Moreover, the black gall stones found at the orifice of the common duct, cannot have been of recent formation, since the contents of the gall bladder show that there was not sufficient pigment shortly before death to supply material for their formation.

If it be urged that the gall stones in the present case were too small to cause obstruction in the bile flow, I would refer to the excellent paper by C. Fenger. ${ }^{3} \mathrm{He}$ proves that quite a small stone in a dilated common bile duct, may, by a "ballvalve action," cause complete obstruction to the entrance of bile into the duodenum.

I incline to the view that the gall stones were the cause of the cirrhosis. Clinically the case resembled the type of hypertrophic cirrhosis, described by Victor Hanot, ${ }^{4}$ of Paris, in 1876 , though much contraction of the newly-formed fibrous tissue probably occasioned the comparatively small size of the liver at the time of death. As in many of Hanot's cases, this patient died with the development of icterus gravis, and, as in most similar cases, nephritic disturbance was present at the end. Hanot's cases were, however, not due to gall stones, which I believe to have been the cause of the whole illness in the present case. In confirmation of my view I would recapitulate shortly a case published in 1875 by Dr. Humbert Mollière.

A woman, aged 70 , was admitted 'in June, 1873 , into the Hôtel-Dieu at Lyons. She had been jaundiced for over two years, but had been able to continue her work until two months before the clate of her admission. when she commenced to lose her strength. The jaundice is said to have commenced on the day following the violent mental emotion of seeing her son again, when he unexpectedly returned home at the time of the FrancoGerman armistice. The liver felt enlarged and hard, the jaundice persisted, and the marasmus increased. The patient died on October $3^{\text {th }}$, I873. At the necropsy the liver was found enlarged and of a green colour. The lower part of the common bile duct was found blocked by a large calculus. In this case it is mentioned that the biliary vessels were hypertrophied and dilated, and contained a blackish powdery material. The main part of the gall bladder was empty, but two or three pouches
in its walls contained a transparent colourless fluid. The size of the in its walls contained
spleen is not stated.

In the present case only comparatively small calculi were found in the common bile duct, and they may have at times allowed the passage of bile, though no bile was actually observed in the fæces when these were examined. This supposition, and the fact that the patient was younger, may account for her having lived a longer time than Humbert Mollière's patient.

An interesting case is described by Dr. C. M. Chadwick. ${ }^{7}$

A woman. aged 36 , who died after copious hæmatemesis, having for nearly six years had persistent jaundice due to gall stones. In this case likewise the liver apparently diminished in size during the latter part of the disease. A remarkable phenomenon in the case was the spontaneous disappearance of the xanthelasma before death. At the necropsy the spleen weighed 2r ounces. but is supposed to have been still larger before the final liæmatemesis. The liver, the surface of which Dr. Chadwick tells me was granular, was of a decidedly green colour and much cirrhosed.

Dr. Chadwick was kind enough to- send me microscopic sections of the liver (prepared by Mr. W. A. Stott), and without denying that parts of the sections somewhat recall Charcot's interlobular (or, as he called it, "perilobular") arrangement of the inflammatory fibrous tissue, I would mention that, on the whole, both Dr. Chadwick himself and Dr. Rolleston, to whom I showed the specimens, agree that

2 Compare Charcot's case, quoted in the Arch. de Phys., second serics, vol. iii., p. 295, observation viii.

4 Victor Hanot, Etude sur une forme de Cirrhose Hypertrophique du Foie (avec Ictère Chronique). Paris, 1876

Lyon AĹdical, vol, xviii., p. I98.

6 Dr. Chadwick's patient (1 e next mentioned case), who was only ${ }_{3} 6$ years old, lived a still longert ime-nearly six years.

7 British Medical Jocrial, i395, vol. i, p، 1143 
the fibrous distribution in the sections resembles that of ordinary cirrhosis.

H. Mayer, ${ }^{\wedge}$ J. Wickliam Legg, ${ }^{9}$ and others, but especially Charcot and Gombault ${ }^{10}$ (I 876 ), have shown experimentally that a cirrhosis of the liver in animals follows ligature of the common bile ducts. In I876 MM. Charcot and Gombault published their well-known paper on the different forms of hepatic cirrhosis, ${ }^{11}$ in which they endeavoured to establish that there are three main types of cirrhosis.

(a) A form of cirrhosis, which they attributed to obstruction in the bile ducts ("biliary cirrhosis"), such as by malignant disease or calculus in the common bile duct. Of this form they regarded as a variety the group of cases described by Hanot"12 under the term "hypertrophic cirrhosis with chronic icterus," and believed the anatomical characteristics to be common to both. The main anatomical features, according to them, were (i) considerable increase, as a rule, in the size of the liver, and (ii) a tendency for the newly-formed fibrous tissue to surround the separate hepatic lobules, sometimes entering between the cells into the substance of the lobule; owing to the distribution of the fibrous material they termed this form of cirrhosis perilobular or monolobular (better interlobular or unilobular) cirrhosis.

(b) A "multilobular" cirrhosis, portal cirrhosis, the ordinary hobnail cirrhosis or cirrhosis of Laennec; in this the fibrous growth is supposed to commence around the small branches of the portal vein; it gives rise to fibrous rings of unequal size, which enclose and compress a varying number of hepatic lobules and cause them to atrophy.

(c) A "pericellular" or unicellular form of cirrhosis, as found in certain cases of congenital syphilitic disease of the liver.

Charcot's description of the microscopic appearances in cases of biliary cirrhosis has been confirmed by many observers, but by others it has been called in question. It is probable, indeed, that there are many cases of cirrhosis due to obstruction in the bile ducts, in which the microscopical features differ in whole or part from Charcot's description, and it is certain that in alcoholic cirrhosis the liver may often be enlarged, ${ }^{13}$ and microscopically may sometimes show an apparent increase in bile capillaries. ${ }^{14}$

It is quite obvious that in the present case the liver did not correspond with what one would expect in a typical case of Charcot and Gombault's "biliary" type of hepatic cirrhosis. Many objections may be raised to my attributing the cirrhosis to obstruction by gall stones in the common bile duct. Some of these objections I have already endeavoured to answer; I will now shortly consider some of the others.

1 have already given my reasons for supposing that the cirrhosis in this case was not due to alcohol, but it may be said that the case was one of a mixed cirrhosis, partly due to chronic obstruction in the common bile duct, partly due to alcohol. I cannot of course prove that alcohol took no part in producing the condition in question, but I see no necessity for invoking it as a part cause.

It may be urged that the liver was not hypertrophied sufficiently. Though not much hypertrophied, it was if anything slightly over the normal weight, and was doubtless a

${ }^{3}$ Medizinische Jahrbiicher, Vienna, 1872, p. $\mathbf{3 3}$.

9 St Bartholomew's

IJ Charcot and Gombault, Note sur les altérations du Foie consécu tives a la Ligature du Canal Cholédoque, Archives de Physiologie, 1876, sciond series, vol. iii, p. 272.

11 Charcot and Gombault, Contributions a l'Etude Anatomique des Différentes Formes de la Cirrhose du Foie, Archives de Physiologie. 1876, p. 453 . caused by inflamuation in the small bile ducts. Chronic cases of biliary cirrhosis in children (Trans. Path. Soc., vol. xli, p. 154; Revue Mensuelle des Maladies de l'Enfance, 1895, vol. xiii, p. 310) may, as regards the cause of the cirrhosis, be considered to bear a somewhat similar relation to the rapidly fatal cirrhosis of infants with congenital absence or obliteration of the common bile duct (Trans. Path. Soc., vol. xxvii, p. 178 vol. xxxiv, p. 129; vol. xlvi, p. 76; E. Henoch's Lectures on Children' Diseases, English translation, London, r889, vol. i, p. 28; and John Thomson's On Congenital Obliteration of the Bile Ducts, Edinburgh, 1892) that Hanot's cases of cirrhosis bear to those due to gall stones or malignant disease obstructing the common duct.

$3 \mathbf{A}$. Foxwell, Alcoholic Cirrhosis of the iver, British Medical

14 Dr. Saundby, Trans. Path Soc., vol. ", p. 3or ; A. Foxwell, loc. cit year before the patient's death very much more increased in size than it was at the time of death. Moreover Charcot and Gombault themselves stated that they did not consider hypertrophy of the liver a necessary accompaniment of biliary cirrhosis. ${ }^{15}$ The enlarged liver may doubtless after a time contract like any enlargement due to newly-formed cicatricial tissue.

In reference to the irregular distribution of the inflammatory fibrous tissue, it must be mentioned that the same authors, in describing the fibrous distribution in their biliary type of cirrhosis, wrote $:^{16}$ "Toutefois, cette régularité est loin de s'observer dans tous les cas et sur tous les points." Moreover Dr. Chadwick's case, previously mentioned, confirms the view that Charcot's arrangement of the fibrous tissue is not always typically present in cases of old-standing biliary cirrhosis.

It may be objected that microscopically in the present case there was no dilatation or apparent increase in the number of bile capillaries. Surely, however, as there must be a tendency to obliteration of the minute bile ducts by the inflammatory fibrous tissue, and as the pressure exerted by the contraction of this newly formed tissue gradually causes more and more of the secreting hepatic cells to atrophy, the pressure of secretion, and the consequent distending force in the ducts, must also be diminished. It may even be supposed that in very chronic obstruction the secreting pressure may be reduced to nothing, the cells which remain unatrophied, naving adapted themselves to circumstances and having become accustomed to secrete their bile backwards (that is, into the blood capillaries and lymph vessels). It may possibly further be supposed that the great enlargement of the spleen (as in the present case), probably more often found in biliary cirrhosis ${ }^{17}$ than in ordinary forms of cirrhosis, may be due, not merely to obstructed blood current in the splenic vein, but may in part also be caused by the longcontinued circulation in the blood of some substance normally excreted by the bile, which acts as a chemical irritant to the spleen and causes a very chronic inflammatory enlargement.

I may mention also that Dr. Robert Saundby, ${ }^{18}$ who has gone into the question, considers that increase in the bile capillaries is not a necessarily distinguishing feature of biliary cirrhosis.

When excessively great dilatation of the small ducts has been observed post mortem in cases where calculí have for a long period been blocking the common bile duct, this has doubtless been often due rather to the mucus or muco-pus secreted by the inflamed ducts than to the pressure of mere bile secretion.

I believe that the decided greenish colour of the liver, as seen at the post-mortem examination, may be considered to afford some confirmation to my view of the case. A greenish colour of the liver appears to be always observed in cases of biliary or hypertrophic cirrhosis with chronic jaundice. Dr. Norman Moore, in fact ${ }^{19}$-except for the colour of the fresh liver-thinks it very often difficult to distinguish biliary cirrhosis from alcoholic cirrhosis. Possibly if fresh sections had been cut before hardening some green inspissated bile might have been found in the form of granules contained in the hepatic cells.

I have heard it raised as an objection to the theory of the production of jaundice by obstruction in the bile ducis, that if the common bile duct be ligatured and micro-organisms ${ }^{20}$

\section{Archives de Physiologie, 1876, p. 476.}

17 See Hanot, op. cit. Archives de Physiologie, 1876 , p. 469 . maximum in chronic biliary or "hypertrophic cirrhosis with jaundice" of children, where the splenic tumour may form the chief morbid feature of the case during life (see A. Gilbert and L. Fournier, Rev. Mensuelle de Maladies de l'Enfance, 1895 , vol. xiii, p. 310$)$. In a case of mine, which now believe belonged to this group, the child's spleen weighed $20 \frac{1}{3}$ ounce to the $26 \frac{1}{2}$ ounces of the liver (Trans. Path. Soc., 1895, p. 7r).

19 Discussion on a case shown by Dr. Goodhart at the Pathological Society 20 If the views of those are JodRnal, r889, vol. i, p. 892 .

views of those are correct who maintain that the cirrhosis which follows ligature of the common bile duct is solely due to irrita tion by chronic infection with micro-organisms, one would suppose that a cirrhosis would equally well or even more readily take place, when in addition to the ligature of the common bile duct a biliary cystotomy is made at the same time. That a cirrhosis follows likewise in such cases has, I believe, not yet been proved. In human beings, when no chole cystostomy has been performed, cirrhosis of the liver seems to be a con- 
be excluded, the constant pressure of the bile and mucous fluid in the bile ducts, ought to cause atrophy rather than inflammatory thickening, around them. This objection appears good at first, but on careful examination seems to me theoretically untenable. In the first place, we cannot be certain that the pressure within the ducts is constant. It may decrease and increase by fits and starts; for the hepatic cells are not likely to be secreting at all times at an equal rate; sometimes, moreover, more bile may be absorbed and carried off by the blood vessels and lymph vessels of the liver than at other times, and this may render the pressure within the ducts an intermittent one.

Furthermore, since the writings of Metchnikoff (who by his works on phagocytosis has done almost as much towards explaining some of the phenomena of chronic, non-infectious inflammations, ${ }^{21}$ as the phenomena of the various infectious inflammations), it appears theoretically likely that obstruction to the bile flow leads to chronic inflammation around the small bile ducts. The sequence of events is probably somewhat as follows: The bile ducts are at first distended with bile, and this distension leads to necrosis of some of the hepatic cells immediately in their neighbourhood. The necrosed cells then act as chronic irritants and causes of inflammation; in other words, they attract corpuscles (scavenger cells, etc.) to remove them. Some of these cells remain and become converted into the new fibrous tissue around the small ducts.

In the present case, supposing my view to be the correct one, the question further arises whether, when the patient was first seen after the jaundice had lasted already three years, and when the cirrhotic process was doubtless already very far advanced, an operation for removal of the stones in the common bile duct, if their presence had been diagnosed, could have been of any use. One would hesitate to answer in the affirmative as regards the ultimate result ; even if the operation had been successful in the removal of the actual stones, the hepatic cirrhosis might perhaps have progressed.

Still, the recent experiments of Dr. D. Nasse ${ }^{22}$ may be called to mind. He succeeded in producing an artificial biliary cirrhosis in limited portions of rabbits' livers, by tying, not the ductus communis choledochus, as earlier experimenters had usually done, but single branches of the hepatic duct. In some of his cases, the ligature "ate its way" through the duct wall, and the duct became spontaneously pervious again, peritoneal adhesions preventing the escape of bile into the general peritoneal cavity: From an examination of the liver in these cases, Dr. Nasse considers that he has evidence that the atrophying part of the liver is capable of some amount of regeneration after the obstruction to the bile flow has been removed. It cannot, however, be overlooked that in Nasse's experiments the duration of the obstruction was very short, when compared to the three years, which the obstruction must have lasted in the present case In this connection, Murchison's case No. exxxII, ${ }^{23}$ to which Dr. J. Kraus, of Carlsbad, drew my attention, is of interest. It is that of a middle-aged woman, who had more or less persistent jaundice from gall stones during nearly six years, and then completely recovered. In this case obstruction to the bile flow was clearly not comand on one occasion it is mentioned that she vomited green bile.

A very great difficulty in the question of operative interference is the diagnosis. In this case, we had no definite history of previous biliary colic; how, therefore, without an exploratory operation, could the case have been distinguished from one of Hanot's cases of hypertrophied cirrhosis, not due to gall stones?

The operation of choledocholithotomy, first successfully

stant result of long-continued complete or intermittent obstruction in the common bile duct. At a recent operation at which I was present. where the obstruction to the bile flow was of one year's duration, the surface of the liver appeared as if the fibrous tissue was increased. In A. Koester's case (see Cent. f. inn. Med, 1896, p. 213) of a boy jaundiced for two years (owing to compression of the common bile duct by enlarged Jymph glands), the fibrous tissue in the liver was also increased in amount.

21 See Elias Metchnikoff, Lectures on the Comparative Pathology of Inflammation, English translation, London, 1893, p. 170.

22 Ueber Experimente an der Leber und den Gallenwegen, Langenbeck's Archiv. f. klin. Chirurgie, 1894, vol. xlviii, p. 885.

23 c. Murchison, Clinical Lectures on Diseases of the Liver, third editior, London, r 985 , p. 417 performed in 1890 by L. G. Courvoisier, ${ }^{2+}$ has very many. times already been successful. Such recent successes, as those recorded by Fenger ${ }^{25}$ and others, are notewortliy. Occasionally also the stone can be crushed between the fingers, through the walls of the duct, and the fragments pressed onwards through the orifice into the duodenum, as. was lately successfully accomplished by Professor Sonnenburg. ${ }^{26}$

In the present case, however, the marked hæmorrhagic tendency, as evidenced by epistaxis and hæmorrhoidal bleeding, would have constituted a special danger for any operative interference.

I know of no case where jaundice, due to obstruction in the common bile duct, has lasted three years, in which an operation has actually been performed, excepting one case recorded by Dr. Hans Kehr, of Halberstadt. 27 . It was that ofi id woman, aged 40, who ten years previously had suffered frono cholelithiasis, and had been jaundiced for the last four years. The jaundice was deep, the liver was enlarged, but the gall bladder could not be palpated; the patient was emaciated and suffered from pruritus. At the operation three large calculi were removed from the common bile duct; but unfortunately the patient died of septic peritonitis due to extravasation of fæcal matter from a spot in the transverse colon where some adhesion with the gall bladder had been torn through during the operation. The state of the liver at the necropsy is not mentioned. Even when the cause of obstruction in the common bile duct cannot be removed, the patient might sometimes be relieved by a cholecystostomy from the intolerable itching due to the jaundice. In cases where the obstruction is due to malignant disease thismeasure could, of course, only be palliative, ${ }^{28}$ but when due to calculi in the common bile duct, the cirrhotic process in the liver might be prevented or delayed, and the calculi themselves might perhaps be removed later on.

I will only add, in conclusion, that if one leaves out of the question cirrhosis from syphilitic scarring and some (etiologically doubtful) forms of cirrhosis, such as the rare " pigmentary cirrhosis with diabetes "first described by Hanot and Chauffard in 1882, the types of cirrhosis may, I believe, be grouped as follows :

I. The ordinary form, usually due to alcohol, in which thecirrhotic process probably commences around the branches of the portal vein. The liver may be either enlarged or diminished in this form of cirrhosis.

2. The hypertrophic and biliary forms of Hanot and Charcot associated with chronic jaundice, in which the cirrhotic process probably commences around the minute bile duets.

3. A kind of cirrhosis met with in cases of splenic anæmia ${ }^{2 *}$ in which the cirrhosis of the liver appears to follow chronic enlargement of the spleen. Possibly in these rare cases the cirrhotic process commences about the lymphatic radicals in: the liver; at least part of the process would then correspond: to Charcot's unicellular or pericellular form of cirrhosis. In many cases of congenital syphilitic disease of the liver in infants the distribution of the cirrhotic process is chiefly intercellular.

The present case affords, I believe, an illustration of the fact that in distinguishing post-mortem specimens of biliary cirrhosis, and Hanot's type of hypertrophic cirrhosis, from cases of ordinary cirrhosis, the main history of the case. during life is of as great importance as the special anatomicopathological features presented by the liver after death. The paper will, however, I hope, be found to contain some matter of interest in other directions than this.

24 L. G. Courvoisier, Casuistisch-statistische Beitraege zur Pathologie umais Chirurgie der Gallenwege, Leipzig, I8go. 26 Berl klin Woch.

I896, p. 241 .

chrift für Chirurgie, 1894, vol. xxxviii, p. $36 \mathrm{r}$

28 Cf. Dr. H. D. Rolleston's remarks on this subject in his paper or. Primary Carcinoma of the larger Bile Ducts, Medical Chronicle, January,

${ }_{2 y}^{89}$ Dr. Banti, of Florence, was, 1 believe, first to describe it. Dr. Douglas: Stanley and others have directed attention to it in England.

Successful Vaccination.-Dr. F. W. Sheard, Public Vaccinator for the Put $\nabla$ District, has received, for the fiftlx: time, an award from the Local Government Board for efficient. ra ?cination in his district. 